\title{
La acción directa \\ y el derecho de defensa del asegurado*
}

\section{The direct redress against the insurer and the insured'right of defense}

\author{
DiAnA ARIZA SÁNCHEZ**
}

\section{RESUMEN}

No hay duda que dentro de la normativa colombiana, la consagración de la acción directa en contra de las aseguradoras constituye un mecanismo práctico y garantista, que les facilita a las víctimas de eventos constitutivos de responsabilidad civil un acceso menos tortuoso a la realización del derecho a la reparación integral. No obstante, el ejercicio de dicha acción acarrea una serie de problemáticas procesales y sustanciales de cara al asegurado (civilmente responsable), cuya resolución dista de ser pacífica. Particularmente, dichas dificultades se sintetizan en la necesidad o no de integrar en el contradictorio al asegurado, como quiera que su responsabilidad civil será un punto insoslayable de controversia en el litigio entablado en contra de la aseguradora. El presente artículo pretende explorar el marco jurídico que permite comprender correctamente la anotada dificultad, así como proponer una respuesta al mismo, desde la perspectiva del derecho colombiano.

Palabras clave: acción directa, seguro de responsabilidad civil, asegurado, litisconsorcio, derecho de defensa del asegurado.

* Fecha de recepción: 2 de mayo de 2019. Fecha de aceptación: 27 de junio de 2019. Para citar el artículo: Ariza D. "La acción directa y el derecho de defensa del asegurado". En Revist@ E-Mercatoria, vol. 18, n. ${ }^{\circ}$ 1, enero-junio, 2019. DOI: https://doi.org/10.18601/16923960. v18n1.02

** Abogada de la Pontificia Universidad Javeriana, especialista en Derecho de Seguros de la misma Universidad, con maestría en Derecho de Daños de la Universitat de Girona-España. Abogada de litigios en Vélez Gutiérrez Abogados. Bogotá, Colombia. dianaarizasanchez2@ gmail.com 


\begin{abstract}
There is no doubt that the legal standing that the Colombian law establish for the victim of a tort, in order to file a legal claim against the insurer of civil liability, constitutes a practical and beneficial mechanism, which facilitates such victims a less tortuous access to their right to a full compensation. However, such legal standing takes to a series of substantial and procedural issues regarding the insured (tortfeasor), which answer is far from being pacific in the Colombian legal systems. Particularly, such problems can be synthetized in the need or not of calling the insured to the judicial proceedings, due to the fact that his civil liability will be an unavoidable legal issue in the litigation initiated against the insurer. The present article pretends to explore the legal frame that allows to correctly comprehend the said difficulty, as to propose an answer to it, from the Colombian law perspective.
\end{abstract}

Keywords: direct redress against the insurer, civil liability insurance, insured, joint litigation, the insured' right of defense.

\title{
INTRODUCCIÓN
}

La acción directa es frecuentemente definida como el derecho que tiene el tercero beneficiario de un seguro de responsabilidad civil (víctima) para reclamar ante una compañía aseguradora el pago de los perjuicios que sean atribuibles a la actuación activa u omisiva de quien funja como asegurado ${ }^{1}$. Es preciso aclarar que este derecho no es autónomo ni independiente del contrato de seguro de responsabilidad civil. Todo lo contrario, si bien "el derecho que extiende al perjudicado los efectos del contrato brota de la propia ley, lo cierto es que aquél no podrá pretender cosa distinta de la que eficazmente delimite el objeto negocial, por lo menos en su relación directa con el asegurador, que como tal está sujeta a ciertas limitaciones" ${ }^{\prime 2}$. En otras palabras, si bien la ley reconoce el derecho a que la víctima reclame de forma directa a la aseguradora el pago de los perjuicios que le sean causados, tal petición no es autónoma del contrato de seguro dado que el asegurador sólo responde dentro de dicho marco contractual.

Pese a la claridad conceptual que existe en torno a la consagración de la acción directa en el contrato de seguro como un derecho en cabeza de las

1 ÁnGEl Vigil-DuATE, La acción directa del tercero perjudicado contra el asegurador de responsabilidad civil, Revista Ibero-Latinoamericana de Seguros, vol. 17, n. ${ }^{\circ} 28$ (2008), p. 46.

2 Corte Suprema de Justicia. Sala de Casación Civil. Sentencia del 10 de febrero de 2005. M.P. Jaime Alberto Arrubla. Rad. 7614 
víctimas de un evento dañoso, lo cierto es que, en el devenir de su ejercicio $y$, particularmente, por el hecho de concebirse hoy en día, al menos en la jurisprudencia, que entre el asegurado y la aseguradora se erige un litisconsorcio de carácter facultativo, surgen interrogantes sobre si en los eventos en que el tercero perjudicado prescinda de la comparecencia del asegurado dentro del proceso que se siga en contra de la aseguradora, se pueden afectar aspectos sustantivos del derecho de defensa del asegurado. De esta manera, el presente artículo tiene como propósito examinar, por una parte, si el ejercicio de la acción directa sin la comparecencia del asegurado vulnera el derecho de defensa de éste $y$, por otra parte, si tal vulneración conlleva a que, tanto en los seguros de responsabilidad civil voluntarios como obligatorios, se debiera sostener que entre el asegurado y la compañía aseguradora se conforma un litisconsorcio de carácter necesario.

Para ello, se empezará por estudiar la consagración normativa de la acción directa en el ordenamiento jurídico colombiano, así como la justificación de la existencia de dicha figura en los seguros de responsabilidad civil voluntarios y obligatorios. A continuación, se pasarán a explorar los presupuestos jurídicos que se deben configurar para que el tercero perjudicado pueda ejercitar de manera satisfactoria la acción directa. En este punto, centraremos nuestra atención en el tercero de los requisitos establecidos para tal finalidad, a saber: la prueba de la responsabilidad civil del asegurado por los daños en que la víctima soporte la reclamación que formule en contra de la compañía aseguradora. Hacer énfasis en este aspecto resulta fundamental, dado que es precisamente en el momento en que se analiza la responsabilidad del asegurado sin la presencia del mismo dentro del proceso judicial, cuando el derecho de defensa de este puede resultar transgredido. Finalmente, con el propósito de subsanar la posible afectación del derecho de defensa del asegurado, se planteará la posibilidad de concebir la existencia de un litisconsorcio necesario entre la compañía aseguradora y el asegurado.

\section{ANTECEDENTES LEGISLATIVOS Y CONSAGRACIÓN LEGAL DE LA ACCIÓN DIRECTA EN EL DERECHO COLOMBIANO}

La primera norma que se refirió a la acción directa en el ordenamiento jurídico colombiano fue el artículo 954 del Código de Comercio de $1958^{3}$. En dicha disposición normativa se negó de forma expresa el ejercicio de la citada acción al damnificado otorgándole al mismo, únicamente, la facultad para desplegar todas las actuaciones conducentes para lograr que el causante del

3 Artículo 954 "El seguro de responsabilidad civil no es un seguro a favor de terceros. El damnificado carecerá en tal virtud de acción directa contra el asegurador.

Este principio no obsta para que el asegurador adopte las providencias que estime conducentes a fin de evitar que el asegurado derive ganancia o lucro del contrato". 
daño le entregue la suma que le hubiese sido transferida por la aseguradora para indemnizar a las víctimas del siniestro. La comentada prohibición fue reiterada por el artículo 1133 del Código de Comercio de 1971, bajo el argumento según el cual "el seguro de responsabilidad civil no es un seguro a favor de terceros ${ }^{\prime \prime}$.

Con ocasión de la expedición de la Ley 33 de $1986^{[5]}$, la prohibición analizada se atenuó, permitiendo a las víctimas de accidentes de tránsito acudir de forma directa ante la aseguradora que hubiese expedido el seguro obligatorio de accidentes de tránsito para obtener la indemnización de sus perjuicios. De acuerdo con los debates que antecedieron a la promulgación del mentado articulado, la consagración de la acción directa para este tipo de seguros obligatorios se permitió bajo el entendido de que dichos contratos aseguraticios se suscribían "en beneficio de terceros, sin que estos hayan tenido parte en el contrato $[\ldots]^{\prime \prime}$. Nótese cómo la justificación empleada para reconocer la posibilidad de que la víctima ejerza la acción directa en seguros de carácter obligatorio, denota que el principal objetivo de la contratación de estos seguros es garantizar que los terceros afectados por la realización de algunos eventos considerados socialmente importantes, como lo es, por ejemplo, la conducción de vehículos automotores, sean indemnizados de forma rápida y sin dilaciones por las compañías aseguradoras. Es decir, a diferencia de lo que sucedía hasta este momento con los seguros de responsabilidad civil voluntarios, los seguros de carácter obligatorio no tenían como principal objetivo la protección del patrimonio del asegurado.

No obstante, da la impresión que la diferencia que existía en el ejercicio de la acción directa entre los seguros obligatorios y voluntarios se desvaneció leventemente con la expedición de la Ley 45 de 1.990, como quiera que ésta, en su artículo 87, permitió el ejercicio de la acción directa en cualquier clase de seguro de responsabilidad civil. Esta variación fue posible debido a que el artículo 84 de la precitada normativa estableció, sin distinción alguna, que el propósito del seguro de responsabilidad civil en cualquiera de sus modalidades era el resarcimiento la víctima y no la simple protección patrimonial del asegurado. De esta manera, el seguro de responsabilidad civil voluntario pasó

4 Artículo 1133. "El seguro de responsabilidad civil no es un seguro a favor de terceros. El damnificado carece en tal virtud, de acción directa contra el asegurador"

5 Ley 33 de 1986 el cual consagra que: "El seguro por daños a las personas causados en accidentes de tránsito será obligatorio y el perjudicado tendrá acción directa contra la aseguradora".

6 ANDRÉS JOSÉ PATIÑO ESCOBAR, El derecho de subrogación en materia de SOAT en Colombia (tesis de Grado para optar al título de especialista en derecho privado, Universidad Pontificia Bolivariana, 2012), p. 16. 
de tener como principal objetivo cubrir "los perjuicios que sufra el asegurado, para proceder a amparar los perjuicios patrimoniales que cause el asegurado" ${ }^{17}$.

Sin embargo, aun cuando en la actualidad en el ordenamiento jurídico colombiano el seguro de responsabilidad civil, en cualquiera de sus modalidades, propende por la protección de la víctima, el alcance de dicho argumento debe matizarse, según si nos encontramos ante un seguro de responsabilidad civil obligatorio o a uno de carácter voluntario, toda vez que la protección de la víctima en estas dos clases de seguros encuentra una justificación diferente, según el contrato de seguro ante el cual nos encontremos.

\section{JUSTIFICACIÓN DE LA EXISTENCIA DE LA ACCIÓN DIRECTA EN LOS SEGUROS DE RESPONSABILIDAD CIVIL VOLUNTARIOS Y OBLIGATORIOS}

A pesar de que la acción directa fue concebida por el legislador con el propósito de dotar a los terceros afectados de las herramientas necesarias para obtener la indemnización de sus perjuicios, es imperativo resaltar que tal derecho adquiere diferentes matices en función de la naturaleza obligatoria o voluntaria del contrato de seguro ${ }^{8}$. Por consiguiente, resulta indispensable comprender las razones que justifican la consagración del citado derecho en las modalidades enunciadas, ya que sólo de esta manera será viable sopesar los beneficios que reporta su utilización de cara a los problemas procesales que devienen de la existencia de tal figura.

Los seguros de responsabilidad civil obligatorios son aquellos cuya contratación se exige con el propósito de proteger a los terceros que resulten perjudicados por actividades que, vía jurisprudencial o legislativa, se han definido como de importancia social ${ }^{9}$. De esta manera, los seguros de carácter obligatorio cumplen con fines de justicia distributiva, toda vez que a través de los mismos se busca lograr la reparación de aquellas víctimas de siniestros que devengan del desarrollo de actividades que, si bien son deseables por la comunidad, pueden causar daños que no deben ser asumidos por quienes resulten afectados con su realización ${ }^{10}$. Para Leibniz el seguro "obligatorio"

7 Corte Suprema de Justicia. Sala de Casación Civil. Sentencia del 18 de mayo de 1994. M.P. Edgardo Villamil Portilla. Rad. 4106.

8 Osvaldo Lagos Villarreal, Fundamento y régimen de la vinculación entre el tercero perjudicado y el asegurador voluntario de responsabilidad civil: una cuestión de derecho privado, Revista Chilena de Derecho Privado n. ${ }^{\circ} 26$ (2016), p. 224.

9 Sobre el particular, Ossa es enfático en señalar que la acción directa debe ser considerada como "consustancial al seguro obligatorio de R.C. entrañable a la función social a que lo encauza prioritariamente la ley". J. EFRÉN OSSA G, Teoría General del Seguro - El contrato (Bogotá: Temis, 1991), p. 452.

10 " [...] En primer lugar, la mayor diferencia entre la justicia distributiva y la justicia correctiva tiene que ver con su ámbito de aplicación. La justicia distributiva y la justicia correctiva 
se formula como una respuesta al problema del riesgo. En el sentir de este autor, el citado seguro "permite reducir la distancia entre el estado social ideal (que es gobernado por la justicia distributiva) y el estricto estado de derecho (fundado sobre la justicia conmutativa) ${ }^{\prime \prime 11}$, siendo por ende, en la mayoría de los $\operatorname{casos}^{12}$, "jurídicamente innecesaria la determinación de la responsabilidad, lo único que importa es vincular al dañado con el ámbito de protección que otorga derecho a indemnización o con la prestación de seguridad social"13. Debido a lo expuesto, el ejercicio de la acción directa en los seguros obligatorios no puede tener otro objetivo sino el de garantizar a los terceros que resulten ser víctimas de contingencias de obligatorio aseguramiento, la obtención de la indemnización de sus perjuicios de manera rápida y sin mayores contratiempos ${ }^{14}$.

tiene que ver con su ámbito de aplicación. La justicia distributiva se ocupa de las relaciones entre el individuo y la comunidad. La justicia correctiva regula las relaciones privadas de las personas. Para la justicia distributiva lo relevante es la posición del individuo como miembro del grupo social. Su pertenencia a la comunidad fundamento sus derechos sobre una porción de los recursos de acuerdo con el criterio político adoptado. En cambio, para la justicia correctiva lo único relevante es lo que hizo el individuo. El hecho de que él haya dañado es conceptualmente indistinguible del hecho de que otro haya sufrido un daño. dañar y sufrir un daño son dos formas de considerar un mismo evento. Por esta razón, el daño supone una violación de la igualdad que debe ser rectificada. Las cualidades personales de los involucrados son completamente irrelevantes desde esta perspectiva. Otra diferencia, aunque íntimamente relacionada con la anterior, es que la justicia distributiva y la justicia correctiva son dos formas de justicia que resultan apropiadas en situaciones distintas. La justicia distributiva presupone la existencia de algún recurso común que debe ser repartido. La justicia correctiva presupone lo contrario: que los recursos con que cuentan los individuos les corresponden, y son suyos para emplearlos del modo que crean más conveniente a fin de desarrollar el plan de vida que escojan. Una interferencia con esos recursos supone una interferencia con la persona misma. Estas interacciones constituyen el objeto de la justicia correctiva". Diego M. PAPAYANNIS, Comprensión y justificación de la responsabilidad extracontractual (Madrid: Marcial Pons, 2014), pp. 192-193.

11 PierRe Rosanvallon, La nueva cuestión social repensar el estado providencia (Buenos Aires: Ediciones Manantia,1995), p.18.

12 Es importante resaltar que existen seguros obligatorios, en los que la imputación de responsabilidad al asegurado resulta necesaria para que se puedan afectar las coberturas suscritas. Por ejemplo, en los seguros de responsabilidad civil profesional médica, por regla general, se debe atribuir responsabilidad al galeno o a la institución médica asegurada, para que se pueda afectar el seguro.

13 Osvaldo Lagos VillarReal, Fundamento y régimen de la vinculación entre el tercero perjudicado y el asegurador voluntario de responsabilidad civil: una cuestión de derecho privado, Revista Chilena de Derecho Privado n. ${ }^{\circ} 26$ (2016), p. 196.

14 " $[. .$.$] parece claro que el seguro de responsabilidad obligatorio se realiza en todo caso$ para proteger al tercero perjudicado de la hipotética insolvencia del causante del daño, ya que si dicho contrato pretendiera proteger el interés del tomador no sería obligatoria su realización" MARIANO HERNÁNDEZ ARRAZ, La Acción Directa como Instrumento de Garantía (Madrid: publicaciones del Real Colegio de España, 2005), p. 77. Otras razones que han legitimado la creación de seguros de responsabilidad obligatorios se fundamen- 
Por el contrario, en los seguros de responsabilidad civil voluntarios, la posibilidad de que la víctima de un hecho dañoso pueda acudir directamente a la aseguradora encuentra su fundamento, no en necesidades de justicia distributiva como las que subyacen a la estructuración de los seguros obligatorios ${ }^{15}$, sino en razones de justicia correctiva, esto es, determinadas "por la necesidad de satisfacer deberes correlativos entre sujetos que surgen de relaciones privadas $^{116}$. Es preciso aclarar que la concepción justicia correctiva que se acogerá para efectos del presente análisis será la definida por Jules Coleman como "concepción mixta", según la cual, "la justicia correctiva impone sobre los agentes dañadores el deber de reparar sus incorrectos y las pérdidas injustas que estos causan"17. Por ende, el ejercicio de la acción directa surge como un mecanismo con el que cuentan los terceros afectados para obtener la efectiva reparación de las pérdidas injustas que sufrieron como consecuencia de un hecho imputable al asegurado que se encuentre cubierto por un seguro de carácter voluntario. Lagos Villareal plantea como objetivos de la consagración de la acción directa en lo seguros voluntarios los siguientes:

- Evitar el enriquecimiento injusto del asegurado. Este supuesto se puede configurar cuando el asegurado no pague a la víctima la indemnización a la que esta última tenga derecho, aun cuando la aseguradora hubiese transferido al asegurado tal monto de dinero ${ }^{18}$.

tan en que "la reparación de las víctimas se haga en mayor cantidad de casos posible, que sea rápida, que también dentro de lo posible garantice una igualdad de tratamiento para todas, que cubra tanto lo daños corporales como los daños a los bienes $\mathrm{y}$, desde luego, que el sistema permita a la vez que quede protegido, así sea parcialmente el patrimonio de los responsables". ANDRÉS ORDOÑEZ, El contrato de seguro. Ley 389 de 1997 y otros estudios (Bogotá: Universidad Externado de Colombia, 1998), p. 136.

15 "El fundamento del establecimiento de una obligación de asegurarse- que implica en definitiva una obligación de concluir un contrato- ha de buscarse por consiguiente en la ampliación del campo de la responsabilidad civil y en su evolución, que pretende cubrirse haciendo recaer las consecuencias de esa responsabilidad civil -el nacimiento de la deuda a cargo del causante de determinados hechos dañosos- sobre un asegurador con la finalidad de protección del perjudicado, al existir un deudor solvente, al propio tiempo que se liberaba al responsable de esa deuda. por ello se ha podido decir que el establecimiento de la obligación de contratar un seguro de responsabilidad constituye sin duda una de las características actuales más notables del Derecho moderno de seguros". FERNANDO SÁnCHEZ CALERO, Líneas generales de la evolución de la responsabilidad civil y de su seguro, Revista Ibero-Latinoamericana de Seguros JAVEGRAF, n. ${ }^{\circ} 15$ (2000), p. 65.

16 Osvaldo Lagos VillarReal, Fundamento y régimen de la vinculación entre el tercero perjudicado y el asegurador voluntario de responsabilidad civil: una cuestión de derecho privado, Revista Chilena de Derecho Privado n. ${ }^{\circ} 26$ (2016), p. 195.

17 Jules L. Coleman, Riesgos y daños (Madrid: Marcial Pons, 2010), p. 327.

18 Osvaldo Lagos VillarReal, Fundamento y Régimen de la Vinculación entre el Tercero Perjudicado y el Asegurador Voluntario de Responsabilidad Civil: Una Cuestión de Derecho Privado, Revista Chilena de Derecho Privado, n. ${ }^{\circ} 26$ (2016), p. 193. 
- Evitar la dilución del monto asegurado. El problema que se intenta plantear en este punto hace referencia a aquellos eventos en que, a pesar de que el dinero para indemnizar a la víctima hubiese sido entregado al asegurado, el mismo no pueda ser transferido a dicho tercero por configurarse, por ejemplo, una situación de insolvencia del asegurado que impida realizar pagos individuales en desmedro del conjunto de acreedores que, teniendo un mejor derecho que la víctima, se encuentren persiguiendo sus bienes ${ }^{19}$.

- Evitar el desgaste del sistema procesal y los altos costos que para la víctima puede generar adelantar dos procesos, uno en el contra del asegurado para que se declare la responsabilidad frente al hecho en que fundamenten sus pretensiones, y otro en contra de la entidad aseguradora para que la misma realice el pago correspondiente con afectación a la póliza adquirida por el asegurado que resulte condenado en el primer proceso ${ }^{20}$. De esta manera, la acción directa dota de legitimación en la causa por activa a la víctima de un siniestro para que, en un mismo proceso, demande directamente a la entidad aseguradora y al asegurado a efectos de que se discuta la responsabilidad de este último y la posibilidad de afectar la cobertura del seguro. Nótese como, para dar cumplimiento a esta finalidad, resulta adecuado concebir que entre el asegurado y la aseguradora se configura un litisconsorcio de carácter necesario, ya que de no ser así, es decir, de concebirse que entre la aseguradora y el asegurado se estructura un litisconsorcio de carácter facultativo, la víctima podría, quizá por encontrarse mal asesorada, iniciar dos procesos independientes produciéndose el desgaste procesal que, en efecto, se pretende evitar. Esta precisión se realiza para poner de presente que la posible comprensión de un litisconsorcio necesario en el caso que nos ocupa no se contrapone a los principios de justicia correctiva que subyacen a la existencia del seguro de responsabilidad civil voluntario.

Con base en lo expuesto, es factible concluir que si bien la consagración de la acción directa en los ordenamientos jurídicos se encuentra permeada por la necesidad de proteger y garantizar la efectiva reparación de los terceros perjudicados, no puede perderse de vista que la aproximación al análisis de tal figura necesariamente tendrá que matizarse de acuerdo si nos encontramos frente a seguros de responsabilidad civil voluntarios u obligatorios. Mientras

19 Ibid, p. 193

20 Ibid, p. 194. Sobre este mismo punto, vale la pena mencionar que Reglero Campos señala como objetivo de la acción directa en los seguros voluntario "entendida en términos generales como derecho del tercero frente al asegurador, la acción directa es consecuencia del deseo del legislador de otorgarle una mayor protección cuando el causante está asegurado, protección que obviamente el tercero puede no tener en caso de no existir seguro y que parece querer agilizar la reclamación y el cobro de la indemnización. [...]" FeRNANDO Reglero Campos, Ley del Contrato de Seguro (Navarra: Aranzadi, 2007), p. 1103. 
que en los primeros la consagración de la acción directa encuentra su fundamento en la necesidad de que efectivamente se logre restablecer el desequilibrio que se pudo haber perdido como consecuencia de la producción de un daño injusto (justicia correctiva), en los segundos la existencia de la acción directa busca afianzar la protección de ciertos daños que han sido catalogados como de importancia social, con independientemente de la responsabilidad del asegurado en su causación (justicia distributiva).

\section{PRESUPUESTOS JURÍDICOS PARA EL EJERCICIO DE LA ACCIÓN DIRECTA}

Para que el ejercicio de la acción directa devenga en una sentencia favorable en favor del tercero beneficiario que haga uso de ella, se deben verificar tres requisitos: en primer lugar, se debe acreditar la existencia de un contrato de seguro válido que ofrezca cobertura sobre los hechos que comprometan la responsabilidad del asegurado. En segundo lugar se debe verificar si el daño que fue causado a la víctima se encuentra cubierto por el seguro de responsabilidad civil que se pretende afectar y, en tercer lugar, se debe probar que el asegurado es civilmente responsable por los daños en que la víctima soporte la reclamación que formule en contra de la compañía aseguradora ${ }^{21}$. La configuración del primer y segundo requisito no advierte mayor complejidad, como quiera que el cumplimiento de los mismos dependerá de la labor probatoria de la parte actora. Empero, no sucede lo mismo con el tercero de los requisitos analizados, dado que es precisamente el cumplimiento de este último sin la presencia del asegurado dentro del proceso judicial, cuando es posible afirmar que el derecho de defensa del asegurado puede vulnerarse. Por ello, centraremos nuestra atención en este último aspecto.

De acuerdo con la legislación colombiana, la aseguradora sólo deberá pagar los perjuicios que reclame la víctima de un hecho dañoso si ésta logra demostrar que el asegurado es civilmente responsable por la producción del daño cuya reparación se encuentra reclamando. De esta manera, si el asegurado "no resulta responsable del daño a él atribuido, tampoco resultará obligado el asegurador (situación funcional de dependencia) $)^{\prime 22}$.

21 De acuerdo con la Jurisprudencia de la Corte Suprema de Justicia, para el ejercicio de la acción directa se requiere «acreditar de manera simultánea la existencia de póliza que cubra dicho amparo y la obligación de indemnizar, debidamente cuantificada, como consecuencia de situaciones constitutivas de "responsabilidad civil", las cuales determinan la ocurrencia del suceso incierto que origina su derecho". Corte Suprema de Justicia. Sala de Casación Civil. Sentencia del 5 de julio de 2012. M.P. Edgardo Villamil Portilla. Rad. 2005-00425-01.

22 Carlos Ignacio Jaramillo Jaramillo, La acción directa en el seguro de responsabilidad civil en América Latina, Revista Ibero-Latinoamericana de Seguros JaVEGraf, n. ${ }^{\circ} 8$ (1996), p. 149 . 
Según López Blanco, el cumplimiento del presupuesto analizado no deviene en la configuración de un litisconsorcio pasivo necesario, en tanto "no se presenta el requisito esencial estructurante de la figura, de identidad sustancial, lo cual se evidencia en que no existe comunidad de suerte, pues bien puede suceder que la aseguradora triunfe y que el damnificado, que no demandó al asegurado, inicie en su contra proceso ordinario $[\ldots]^{\prime \prime 23}$. Así las cosas, para el citado autor, lo que puede a lo sumo llegar a surgir entre las mencionadas partes es un litisconsorcio pasivo facultativo, cuando la víctima decide demandarlos conjuntamente bajo un mismo cauce procesal ${ }^{24}$. En la misma línea, la Corte Suprema de Justicia ha sostenido que no es necesario que se vincule al asegurado al proceso que se tramite en contra de la compañía aseguradora por virtud del ejercicio de la acción directa. Lo anterior, en tanto "el detonante de dicha obligación en cabeza de la compañía aseguradora es la configuración del "hecho externo imputable al asegurado". Distinto es que esa misma circunstancia tenga que posteriormente ser calificada, porque como es apenas natural entenderlo, sin ella no habría lugar a analizar si hubo o no responsabilidad"25. La calificación de la responsabilidad a la que hace mención la citada corporación judicial puede realizarse, conforme ésta lo ha indicado, sin la intervención del asegurado en el mismo proceso que se tramite ante a la compañía aseguradora o en un proceso independiente ${ }^{26}$.

Sin embargo, varios autores disienten de la posición antes esbozada, puesto que consideran que entre la aseguradora y el asegurado se configura un litisconsorcio de carácter necesario. Así pues, para autores como Carlos Ignacio Jaramillo la citación del asegurado debería ser forzosa en el proceso que la víctima incoe en contra de la aseguradora, puesto que, al ser la responsabilidad del asegurado objeto de estudio en dicho trámite, si éste no comparece al proceso se le estaría juzgando sin habérsele oído previamente; supuesto que atenta contra principios constitucionales como el derecho al debido de proceso y el derecho de defensa ${ }^{27}$.

Coadyuvando la línea argumentativa en comento, Juan Manuel DíazGranados sostiene que, entre la aseguradora y el asegurado se configura un litisconsorcio necesario, en tanto al ser el análisis de la responsabilidad del asegurado un supuesto imprescindible para que prospere la acción directa

23 Hernán Fabio López Blanco, Comentarios al Contrato de Seguro (Bogotá: Dupré Editores, 2005), p. 377.

24 Ibid, pp. 377-378.

25 Corte Suprema de Justicia. Sala de Casación Civil. Sentencia del 5 de julio de 2012. M.P. Edgardo Villamil Portilla. Rad. 2005-00425-01.

26 Ibid.

27 CARLOS IGNACIO JARAMILLO JARAMILLO, La acción directa en el seguro de responsabilidad civil en América Latina, Revista Ibero-Latinoamericana de Seguros JAVEGRAF, n. ${ }^{\circ} 8$ (1996), p. 149 . 
ejercida por la víctima, no se podrá realizar tal análisis sin la participación del asegurado, so pena de vulnerársele el derecho fundamental al debido proceso que le asiste a este último. Adicionalmente, el precitado autor sostiene que si bien podría confrontarse la mentada postura, arguyéndose que no es posible que se configure un litisconsorcio necesario dado que la sentencia que emane de un proceso judicial como el descrito no necesariamente resolverá la cuestión litigiosa de manera uniforme, dicho argumento puede desvirtuarse señalando que "la uniformidad de decisión atribuida por algunos al litisconsorcio necesario se predicaría únicamente de la cuestión litigiosa que es común a todos los litisconsortes, en este caso de la pretensión relativa a la declaración de responsabilidad del asegurado, mas no respecto a la segunda declaración que atañe, exclusivamente, al contrato de seguro" 28 .

De esta manera, si bien la tesis que ha prevalecido en la jurisprudencia hace referencia a que entre el asegurado y la aseguradora no se configura un litisconsorcio de carácter necesario, a continuación se pasarán a esbozar, de la mano de los varios autores que disienten de la actual posición jurisprudencial, las razones por las cuales debe considerarse que entre la aseguradora y el asegurado debe existir un litisconsorcio de carácter necesario. No obstante, apartándonos de los citados autores, será precisado que tal relación litisconsorcial de carácter necesario sólo se debería predicar en los seguros de responsabilidad civil voluntarios, no así en los seguros de responsabilidad civil obligatorios.

\section{IV. ¿DEBERÍA CONSIDERARSE QUE EXISTE UN LITISCONSORCIO DE CARÁCTER NECESARIO ENTRE EL ASEGURADO Y LA ASEGURADORA EN LOS EVENTOS EN QUE EL TERCERO BENEFICIARIO DEL SEGURO HAGA EJERCICIO DE LA ACCIÓN DIRECTA?}

Conforme se adujo en líneas procedentes, en el ordenamiento jurídico colombiano se ha sostenido que entre la aseguradora y el asegurado se configura un litisconsorcio de carácter facultativo ${ }^{29}$. Ello significa que la posible víctima

28 Juan Manuel Diaz-Granados, El Seguro de Responsabilidad Civil (Bogotá: Universidad del Rosario, 2012), p. 273. En términos similares se pronunció: Maria Cristina Isaza Posse, El seguro de responsabilidad civil extracontractual Dificultades que se presentan en el mercado colombiano, Revista Ibero-Latinoamericana de Seguros JAVEGRAF, n. ${ }^{\circ} 24$ (2006), p. 152.

29 Estamos en presencia de un litisconsorcio facultativo o voluntario en aquellos eventos en los que la presencia de una pluralidad de demandantes o demandados "no es un requisito necesario para la debida integración del contradictorio por tratarse de relaciones jurídicas diferentes e independientes, pero por razones de conveniencia o economía procesal se permite la definición de ellas en un mismo proceso" HeRnán Fabio LóPEZ BLANCO, Código General del Proceso. Parte General. (Bogotá: Dupré Editores,2017), p. 363. En 
tiene la potestad de escoger si demanda al asegurado o a la compañía aseguradora, sin que sea necesario que se dirija en un sólo proceso en contra de estos de forma conjunta ${ }^{30}$. Por ejemplo, acorde a esta postura, bien podría la parte afectada con el hecho dañoso perseguir en un litigio la reparación de los daños efectivamente cubiertos por la póliza de responsabilidad civil y, subsiguiente o coetáneamente, buscar la indemnización de los perjuicios no cubiertos por el seguro con cargo al patrimonio del asegurado.

No obstante, sostener la configuración de un litisconsorcio facultativo deviene en el caso que nos atañe en un grave problema, puesto que, al ser imperativo, para que prospere la acción directa, la previa declaratoria de responsabilidad civil del asegurado, es claro que, en aquellos eventos en que el tercero perjudicado decidiera ejercer la referida acción sin demandar de forma conjunta al asegurado, el derecho de contradicción y de defensa de este último pueden verse gravemente vulnerados. Lo anterior por cuanto, dentro del proceso judicial que surja a partir de la acción directa incoada en contra de la aseguradora, invariablemente deberá analizarse la configuración o no de los elementos constitutivos de la responsabilidad civil asegurada ${ }_{i}$ los cuales constituyen, en los términos de la correspondiente póliza, la condición suspensiva de la cual pende el nacimiento de la obligación indemnizatoria reclamada a la compañía de seguros. Por consiguiente, en sede de un litigio promovido sólo en contra del asegurador, de forma inexorable se analizará la responsabilidad del asegurado en la producción del siniestro, sin permitírsele al mismo oponerse a los argumentos que en su contra se llegaren a esgrimir.

Los defensores de la existencia de un litisconsorcio facultativo en el caso bajo análisis contraargumentan que, bajo dicho escenario, no se vulnerará el

otras palabras, el litisconsorcio voluntario es aquel que "es permitido por la ley, aunque no exigido por la misma, y que implica una acumulación subjetiva de acciones - y por ende objetiva- ya en una o en ambas de las posiciones jurídico - procesales, y consecuencia de la voluntad del actor o incluso del demandado, según sea inicial o sobrevenido" MARía FERNANDA Vidal PÉREZ, El Litisconsorcio en el Proceso Civil. (Madrid: La Ley, 2007), p. 82.

31 Es importante señalar que para grande seara "en principio, lo más recomendable para el perjudicado será demandar conjuntamente al asegurado y al asegurador, pues su derecho de crédito frente al asegurado es presupuesto necesario para que pueda tener existo la acción directa. Además, en el supuesto de obtener una sentencia con pronunciamientos condenatorios gene a los dos, se podrá dirigir en ejecución contra cualquiera de ellos, salvando así los inconvenientes que se pudieran derivar de la insolvencia en la que pueda incurrir el otro condenado o los límites de la cobertura del seguro. En este caso, el actor no ejercita una pretensión indemnizatoria única frente a una pluralidad de sujetos pasivos de la misma, sino que acumula en una misma demanda las pretensiones indemnizatorias que le competen frente al asegurado y frente al asegurador. Son pretensiones indemnizatorias distintas aunque conexas y, en cierto modo, dependientes, por lo que su ejercicio acumulado en un mismo procedimiento viene permitido por el art 72 lec", PABLO GRANDE SEARA, La extensión subjetiva de la cosa juzgada en el proceso civil (Valencia: Tirant lo Blanch, 2008), p. 427. 
derecho al debido proceso judicial del asegurado, en la medida que, por gracia del principio de relatividad de las sentencias de orden civil, la decisión de mérito condenatoria no lo vinculará ni surtirá ningún tipo de efectos frente al mismo. En otras palabras, en el supuesto enunciado, ante la no participación del asegurado en el proceso, no se configurará el elemento subjetivo propio de la figura de la cosa juzgada para que el fallo que se emita surta efecto de cosa juzgada material en su contra ${ }^{31}$. De hecho, conforme lo menciona Grande Seara, la primera sentencia que sea proferida en contra de la compañía aseguradora -previo el análisis de la responsabilidad del asegurado-, tan sólo "dejará sentir su eficacia refleja" en el nuevo proceso que pueda iniciarse en contra del causante del daño, "al menos en lo que respecta a la existencia o inexistencia del evento dañoso" ${ }^{\prime 32}$. De esta manera, lo resuelto en el primer fallo constituirá tan sólo un hecho jurídico en favor, o bien de las pretensiones de la víctima, o bien de las excepciones de la parte demandada; dando la posibilidad, en todo caso, a la parte a quien no le convenga tal decisión, de desvirtuar el citado hecho probatoriamente.

Este análisis bien podría llevarnos a pensar que el problema en torno a la posible indefensión del asegurado carece de relevancia alguna. No obstante, dado que en el ordenamiento jurídico colombiano, el sistema de valoración probatoria se fundamenta en la sana crítica $^{33}$, un primer fallo que envuelva la

31 La cosa juzgada se caracteriza por tener dos límites: uno objetivo, el cual hace referencia al objeto y a la causa del litigio y, otro subjetivo, que se compone por las personas que hacen parte del litigio. En cuanto al límite subjetivo hace referencia a que "la sentencia no produce cosa juzgada sino entre las mismas partes. No se trata de identidad de personas porque ya sabemos que no todas las personas que concurren a un proceso lo hacen como partes y que no siempre las partes obran personalmente, porque suelen hacerlo por intermedio de sus apoderados o representantes" HeRnando Devis ECHANDiA, Teoría General del Proceso (Buenos Aires: Editorial Universidad, 1985), p. 504.

Este límite resulta de la máxima importancia, como quiera que encuentra su fundamento en el derecho de defensa y de contradicción que, tanto el ordenamiento jurídico colombiano como el español, reconocen. En efecto, "un sujeto que no ha sido parte en el proceso, ni tuvo la oportunidad de serlo y, por lo tanto, no ha tenido ocasión de participar en la formación y configuración del pronunciamiento jurisdiccional que en el mismo recaiga, no se debe ver afectado, a priori, por los efectos de tal pronunciamiento" PABLO GRANDE SEARA, La extensión subjetiva de la cosa juzgada en el proceso civil (Valencia: Tirant lo Blanch, 2008), p. 126. En otras palabras, salvo algunas excepciones, el fenómeno procesal de la cosa juzgada solo se configura frente a las personas que hicieron parte del proceso en el que la sentencia a la que se le atribuya tal efecto fue proferida.

33 Pablo Grande Seara, La extensión subjetiva de la cosa juzgada en el proceso civil (Valencia: Tirant lo Blanch, 2008), p. 428.

33 En el ordenamiento jurídico colombiano el sistema de valoración de pruebas que permea el análisis de los jueces es el de la "sana crítica". Así se evidencia de la lectura del artículo 176 del Código General del Proceso Colombiano. La doctrina y la jurisprudencia suelen definir el sistema de valoración de la sana crítica, como una categoría intermedia entre la prueba legal y la libre convicción. Corte Constitucional de Colombia. Sentencia C.202 del 8 de marzo de 2005. M.P. María Victoria Calle Correa. Para autores como Parra Quijano, 
declaración de la existencia de responsabilidad del asegurado (acaecimiento del siniestro), aun cuando sea valorado como un simple hecho jurídico en el proceso que la posible víctima incoe respecto del causante del daño, podría constituirse en un obstáculo insalvable para la defensa que el asegurado pretenda desplegar. En efecto, como quiera que dentro del sistema de la sana crítica no todos los motivos que mueven al juez a inclinarse por una opción son puestos de presente en la parte reflexiva de la sentencia, es de suponer que varios de los aspectos que pudieron llevar al primer sentenciador a adoptar un pronunciamiento que envuelva la responsabilidad patrimonial del asegurado no serán puestos de manifiesto para tomar la decisión que hará tránsito a cosa juzgada ${ }_{i}$ de tal forma que al asegurado le será sumamente difícil poder entrar a discutir los reparos allí realizados cuando el juez del segundo proceso vuelva a revisar la cuestión.

Con lo anterior, no se quiere poner presente que el sistema de la sana crítica constituya un mecanismo indeseable desde el punto de vista probatorio. Como es evidente, su concepción resulta mucho más sensata y lógica que los arcaicos esquemas impuestos por una estricta tarifa legal probatoria. No obstante, a pesar de sus indudables bondades, caracterizadas por la mayor propensión a una fundamentación racional y lógica de las decisiones jurisdiccionales, no pueden pasarse por alto los efectos que la sana crítica conlleva en tratándose de la explicitación práctica del racionamiento judicial probatorio ${ }^{34}$.

el racionamiento del operador judicial bajo el sistema de la sana crítica toma como parámetros materiales "la atmósfera o ambiente generado por un proceso determinado", así como también "la propia experiencia del funcionario judicial", "la experiencia histórica acumulada en la Administración de Justicia, y, en muchos casos, las reglas producidas en el proceso evolutivo de ciencias, técnicas y artes en los que se apoya la actividad judicial". JaIRO PARRA QUIJANO, Manual de derecho probatorio (Bogotá: Librería del profesional, 2007), p. 248

34 Pese al tinte de racionalidad que se pretende atribuir al sistema de la sana crítica, no puede perderse de vista que - según se puede apreciar de las diferentes definiciones antes trascritas- la valoración que de las pruebas realice el juez con fundamento en la "sana critica" tiene un enorme grado de subjetividad, por cuanto la misma está llamada a realizarse tomando como fundamento la lógica y raciocinio personal del Juez; quien además, como es frecuente, tiende a motivar sus fallos con apreciaciones tales como, "estoy convencido" o "el testigo me resulta creíble" RODRIGo COLOMA CORREA, Realmente importa la sana crítica?, revista chilena de derecho, vol. 39, n. ${ }^{\circ} 3$ (2012), p. 765. De acuerdo con Coloma Correa, precisamente uno de los problemas que deviene de la implementación de la sana crítica, es, precisamente, la dificultad que existe "para denotar formas concretas de valorar la prueba conforme a ella ('no estamos seguros de cuáles prácticas judiciales serían consistentes con la $\left.\mathrm{SC}^{\prime}\right)^{\prime}$. En otras palabras, si bien podría llegarse a afirmar que "están dadas las condiciones para construir definiciones que susciten niveles suficientes de adhesión entre los especialistas", las mismas resultan para "identificar prácticas judiciales representativas de dicha forma de valorar la prueba". RODRIGO COLOMA CORREA, ¿Realmente importa la sana crítica?, revista chilena de derecho, vol. 39, n. ${ }^{\circ} 3$ (2012), pp. 754-755. 
Asimismo, es del caso señalar que también resultará complejo para el asegurado desvirtuar la responsabilidad que se le atribuyó en el primer proceso, en tanto no puede desconocerse que existirá, para el juez que conozca del segundo proceso, el incentivo de no contradecir las conclusiones alcanzadas por parte del primer fallador, a fin de evitar que se configuren respuestas contradictorias a un mismo problema jurídico; siendo dicha contradicción una hipótesis que diáfanamente repugna a todo sistema jurídico que se precie de ser coherente y garante del principio de seguridad jurídica.

De nuevo, en este punto, los defensores de la configuración de un litisconsorcio facultativo en el caso que nos atañe podrían sostener que, una posible alternativa para conciliar la aplicación de la citada figura con la inevitable preocupación que surge de cara al derecho de contradicción del asegurado, está dada por las figuras procesales que le permitirían al asegurado participar procesalmente en el marco de dicha acción, en calidad de tercero interviniente. Así, por ejemplo, encontramos en el derecho colombiano la figura del coadyuvante o de la intervención adhesiva simple. Esta figura procesal hace referencia a "la injerencia de un tercero en un proceso pendiente entre otras personas, con el fin de evitar el perjuicio jurídico que pudiera ocasionarle, como consecuencia de la eficacia refleja de la cosa juzgada, la derrota de una de las partes" ${ }^{135}$. Sin embargo, lo cierto es que, aun en el supuesto en que el asegurado participe en el proceso que se siga en contra de la aseguradora a título de interviene adhesivo simple, esta circunstancia no garantizará que el mismo pueda ejercer su derecho de defensa de manera eficaz. En efecto, de la lectura del artículo 71 del Código General del Proceso ${ }^{36}$, es factible inferir que las facultades adjetivas del coadyuvante se encuentran claramente limitadas por las determinaciones de quien sí es parte procesal. Esto significa que la intervención del asegurado como mero coadyuvante en el seno de una acción

35 Juan Montero Aroca, La intervención adhesiva simple. Contribución al estudio de la pluralidad de partes en el proceso civil, (Barcelona: Editorial Hispano-Europea,1972), p. 160.

36 Artículo 71. "coadyuvancia. Quien tenga con una de las partes determinada relación sustancial a la cual no se extiendan los efectos jurídicos de la sentencia, pero que pueda afectarse si dicha parte es vencida, podrá intervenir en el proceso como coadyuvante de ella, mientras no se haya dictado sentencia de única o de segunda instancia.

El coadyuvante tomará el proceso en el estado en que se encuentre en el momento de su intervención y podrá efectuar los actos procesales permitidos a la parte que ayuda, en cuanto no estén en oposición con los de esta y no impliquen disposición del derecho en litigio.

La coadyuvancia solo es procedente en los procesos declarativos. La solicitud de intervención deberá contener los hechos y los fundamentos de derecho en que se apoya y a ella se acompañarán las pruebas pertinentes.

Si el juez estima procedente la intervención, la aceptará de plano y considerará las peticiones que hubiere formulado el interviniente.

La intervención anterior al traslado de la demanda se resolverá luego de efectuada esta". 
directa se encuentra circunscrita a un espacio procesal claramente delimitado por la voluntad de la aseguradora. Por ende, la materialización del derecho de defensa y contradicción del asegurado se reduce a una participación accesoria, estando subyugado a la estrategia probatoria de defensa que, unilateralmente, decida implementar la aseguradora accionada. Por lo demás, es pertinente llamar la atención, en torno a que el coadyuvante al momento de su vinculación debe asumir el proceso en el estado en que este se encuentre, esto quiere decir que, si el asegurado ingresa al proceso en la citada calidad cuando la etapa probatoria ya hubiere transcurrido, el mismo no tendrá la oportunidad de contradecir las pruebas que con anterioridad a su intervención se hubieran practicado. A modo de ejemplo, basta con señalar que el asegurado no podrá contrainterrogar a los testigos o peritos que hubieren previamente acudido al proceso para declarar sobre su responsabilidad en los hechos.

Así las cosas, son claros los problemas procesales, e incluso ius fundamentales, que supone concebir que entre la aseguradora y el asegurado existe un litisconsorcio facultativo. Bajo tal entendido, es pertinente preguntarse si es viable concebir entre tales obligados un litisconsorcio cuasinecesario. Para dar respuesta a este interrogante, se debe recordar que en el ordenamiento jurídico colombiano la responsabilidad de la compañía aseguradora encuentra su fundamento en los alcances del contrato de seguro, motivo por el cual no es factible afirmar que entre aquella y el asegurado se configure una obligación de carácter solidaria, ni ninguna otra de la que devenga la configuración de un litisconsorte cuasinecesario ${ }^{37}$. Por lo demás, concebir que entre los citados

37 El litisconsorcio cuasinecesario es aquel que presenta características tanto del litisconsorcio necesario, como del facultativo. Autores como Fairén Guillén sostenía que "entre las figuras del litisconsorcio necesario y voluntario se emplaza otra, a veces un tanto obscura y dependiente en puridad más de los tratamientos normativos que de la propia naturaleza de las relaciones jurídicas materiales: es el litisconsorcio cuasi-necesario". VÍCTOR FAIRÉN GuILLEN, Teoría general del derecho procesal. Revista de derecho privado del Instituto de Investigaciones Jurídicas. Serie G estudio, n. ${ }^{\circ} 133$ (1992), p. 143. De acuerdo con Parra Quijano, el litisconsorcio cuasinecesario se configura cuando: "Existiendo varias personas eventualmente legitimadas para intentar una determinada pretensión, o para oponerse a ella, la sentencia es susceptible de afectar a todos por igual, aun en el supuesto de que no hayan participado o no hayan sido citados al correspondiente proceso. No se exige, por tanto, como ocurre con el supuesto del litisconsorcio necesario, que todas esas personas demanden o sean demandadas en forma conjunta". JaIRO PARRA QUIJANO, Manual de derecho probatorio (Bogotá: Librería del profesional, 1992), p. 49. El artículo 62 del Código General del Proceso, además de consagrar esta figura, haciendo énfasis en que, debido a que al litisconsorte cuasinecesario le afecta la sentencia que se va a emitir dentro del proceso, el mismo podrá pedir su vinculación al trámite judicial en cualquier momento. Si dicha petición se produce con anterioridad al decreto de pruebas, el litisconsorte podrá solicitar las pruebas que estime necesarias. Además de las obligaciones solidarias el inciso tercero del artículo 68 del Código General del Proceso, trae consigo otro ejemplo de esta figura, cuando consagra que "el adquirente a cualquier título de la cosa o del derecho litigioso podrá intervenir como litisconsorte del anterior titular. También podrá sustituirlo 
obligados existe un litisconsorcio cuasinecesario resultaría aun peor que suponer que entre aquellos se configura un litisconsorcio facultativo, puesto que, en aquel evento, la sentencia que se llegase a proferir surtirá efecto de cosa juzgada material en contra del asegurado y la aseguradora, sin importar si los mismos concurrieron de forma conjunta al proceso. En decir, de considerarse que existe un litisconsorcio cuasinecesario se anulará por completo el derecho de contradicción de aquel sujeto que no hizo parte del litigio, ya que su presencia no hará falta dentro del proceso para que lo que se decida en el mismo produzca efectos en su contra.

Con fundamento en lo anterior, la mejor alternativa que existe para evitar la configuración de los problemas antes planteados, es considerar que entre la aseguradora y el asegurado se configura un litisconsorcio de carácter necesario $^{38}$. Esta postura resulta totalmente viable, en tanto al tener que definirse necesariamente sobre la responsabilidad del asegurado en el pleito que se siga en contra de la aseguradora en ejercicio de la acción directa, es posible argüir que la participación del asegurado se hace imprescindible a fin de que el mismo pueda ejercer el derecho de defensa y contradicción que le asiste, sin que sea necesario esperar a que el tercero perjudicado lo demandare en otro proceso para oponerse a las afirmaciones que, en su contra, se hubieren realizado en el primer proceso.

Además, no puede perderse de vista que, aunque existan elementos jurídicos que puedan conllevar a que no exista plena comunidad de suerte entre la aseguradora y el asegurado ( $v$.gr. las coberturas de la póliza sólo determinan la responsabilidad civil de la primera), en lo atinente a la configuración del siniestro asegurado, que está en gran parte dado por la existencia de la responsabilidad del asegurado, sin duda sí existe la necesidad de una decisión de mérito uniforme para ambos sujetos. Es más, nótese que si la víctima no

en el proceso, siempre que la parte contraria lo acepte expresamente". En este caso, conforme lo menciona López Blanco, "el adquirente de la cosa o el derecho litigioso, podrá intervenir como litisconsorte por cuanto, así no se haga parte, queda vinculado por la sentencia precisamente por derivar sus derechos de quien era titular de la relación jurídica respectiva cuando se inició el proceso [...]" HeRnán Fabio LÓPEZ BlanCO, Código General del Proceso. Parte General. (Bogotá: Dupré Editores, 2017), p. 370.

38 Se configura un litisconsorcio necesario cuando varias personas deben obligatoriamente comparecer al proceso, "ora en calidad de demandantes, bien como demandados, por ser un requisito necesario para proferir sentencia dada la unidad inescindible con la relación de derecho sustancial en debate que impone una decisión de idéntico alcance respecto de todos los integrantes" Ibid, p. 353. El artículo 61 del Código General del Proceso Colombiano, consagra la existencia del litisconsorcio necesario aduciendo que esta figura procesal atiende a "la naturaleza de la relación jurídica" o se establece por "disposición legal". Sin embargo, lo cierto es que la doctrina ha sido unánime en señalar que "la única fuente del litisconsorcio necesario es la naturaleza de las relaciones jurídicas objeto del litigio, debido a que cuando la ley ordena integrarlo también atiende a la índole de ellas". Ibid, p. 355 . 
demanda al asegurado en otro proceso posterior al que inicie en contra de la aseguradora, el posible causante del daño no contará con la oportunidad de oponerse a los argumentos que en su contra se adujeron, lo cual resulta sumamente perjudicial, por ejemplo, para la imagen y buen nombre del asegurado.

Ahora bien, la postura en comento también resultará deseable para las aseguradoras, no sólo por cuanto contarán con la colaboración del asegurado dentro del proceso para ejercer su defensa, sino porque de esta manera se evitarán procesos que se sigan en su contra luego de que exista un fallo en el que se responsabilice al asegurado; supuesto éste que, generalmente, al presentarse, deviene casi de forma automática en una condena en contra de las compañías, quienes, al desconocer las circunstancias de tiempo, modo y lugar en que se produjo el accidente, les resultará bastante complejo desvirtuar los supuestos fácticos en los que se fincó la condena impuesta en un primer momento al asegurado.

Pese a lo anterior, podríamos preguntarnos en este momento si, aun cuando resulta deseable -a efectos de favorecer el derecho de defensa del asegurado- que se configure un litisconsorcio necesario entre la aseguradora y el asegurado, dicho análisis está llamado a matizarse según si nos encontramos ante un seguro de responsabilidad civil obligatorio o uno de carácter voluntario. La respuesta a este cuestionamiento debe ser afirmativa, ateniendo a que el fundamento que subyace a la consagración de la acción directa en los seguros obligatorios es diferente al que da origen a dicha acción en los seguros voluntarios. De esta manera, si bien en los primeros la acción directa se consagra con el propósito de beneficiar a ultranza a quienes resulten víctimas de un siniestro, existiendo cada vez una mayor a tendencia a pasar por alto el análisis sobre la responsabilidad que pueda surgir en cabeza del asegurado en los segundos la consagración de la acción directa encuentra su origen en un supuesto de justicia correctiva.

Siendo ello así, se deben ponderar los derechos e intereses que, en uno u otro supuesto se buscan proteger con la consagración de la acción directa, de cara al derecho de contradicción que con la consagración del litisconsorcio necesario se busca salvaguardar, a fin de determinar cuál de tales derechos deben prevalecer en uno u otro caso.

Para realizar el ejercicio planteado, es necesario remembrar que la consagración de la acción directa en los seguros de responsabilidad civil obligatorios busca garantizar a las víctimas una rápida indemnización de los perjuicios que sufran, como quiera que los mismos son productos de actividades que, si bien son socialmente deseables, traen consigo, por regla general, un riesgo latente de causar daños a terceros. De esta manera, exigir a la víctima de un daño que en un mismo proceso demande a la aseguradora y al asegurado puede generar un efecto contrario al que el legislador pretende alcanzar con el reconocimiento de la figura en comento. Lo anterior dado que, al tener que demandar el tercero afectado tanto a la aseguradora como al asegurado, es evidente 
que, además de que el litigio se tardará en resolver un poco más, se generarán mayores cargas a las víctimas, quienes, además de tener que notificar a dos partes, tendrán que elevar necesariamente su nivel de diligencia, puesto que se verán en la obligación de refutar los argumentos de defensa que proponga tanto el asegurado como la aseguradora, supuesto este último que devendrá en mayores costos. De hecho, esta mayor inversión podría desincentivar la actuación judicial del perjudicado, teniendo que asumir este último el valor de sus perjuicios. Es decir, se generaría un efecto contrario al que el legislador pretende con el reconocimiento de seguros obligatorios.

Así pues, dada la finalidad del seguro obligatorio y, como quiera que, en todo caso, a pesar de los problemas que devienen de la no participación del asegurado dentro del proceso, el fallo que se emita sin su participación no producirá efecto de cosa juzgada materia frente al mismo, es factible sostener que debería permitirse a la víctima iniciar en contra de la aseguradora, vía acción directa, el proceso judicial para obtener la indemnización de sus perjuicios, sin tener que vincular al asegurado a la litis para tal finalidad.

Todo lo contrario sucede si nos encontramos ante un seguro de responsabilidad civil de carácter voluntario. En estos eventos, la acción directa, de cara al tercero perjudicado, tiene como objetivo evitar que el asegurado eluda su obligación de transferir los dineros que, con afectación del seguro, obtenga para pagar los daños a la víctima; así como también se busca impedir que la víctima tenga que iniciar dos procesos diferentes, uno en contra del asegurado y otro en contra de la aseguradora, para obtener la indemnización de sus perjuicios. En tal sentido, es factible inferir que en esta modalidad de seguros la configuración de un litisconsorcio necesario no afecta en lo más mínimo el cumplimiento de los objetivos de justicia correctiva que subyacen a la permisividad del ejercicio de la acción directa para la afectación de seguros de responsabilidad civil de carácter voluntarios.

Asimismo, no puede pasarse por alto que, a pesar de que la víctima en las dos modalidades de seguros tiene un papel importante, lo cierto es que en el seguro de responsabilidad civil voluntario, la protección del patrimonio del asegurado adquiere una relevancia mucho mayor. De hecho, contrario a lo que sucede con el seguro de responsabilidad civil obligatorio, el seguro de responsabilidad civil voluntario puede adquirirse o no adquirirse, según sin el asegurado desea proteger su patrimonio ante un evento dañoso que pueda debilitar el mismo; sin que tal decisión necesariamente se vea permeada por una preocupación genuina de lograr que las víctimas queden indemnes. De esta manera, imponer a la víctima en este supuesto que dentro de un mismo proceso demande tanto al asegurado como al asegurador, no deviene en una carga excesiva para esta última y, sí evitará que se vulnere el derecho de contradicción del asegurado.

En este punto, es pertinente llamar la atención en torno a que, si el lector está de acuerdo en torno a que entre el asegurado y la aseguradora existe 
un litisconsorcio de carácter necesario, le podría resultar controversial la diferenciación que se plantea de cara al ejercicio de la acción directa en los seguros de responsabilidad civil obligatorios, en la medida en que conlleva la matización o flexibilización de un derecho fundamental, como lo es el derecho de defensa, con un notorio pedigrí histórico y constitucional. Por ello, para internar responder las posibles críticas que en torno a este aspecto puedan plantearse, es posible recurrir a los siguientes dos argumentos:

En primer lugar, se debe remembrar que, conforme lo ha reconocido la Corte Constitucional Colombiana ${ }^{39}$, los derechos fundamentales -entre ellos el derecho de defensa y de contradicción- no son absolutos, por lo que, en determinadas circunstancias los mismos pueden llegar a limitarse ante la necesidad de que prevalezcan otros derechos fundamentales o bienes constitucionalmente protegidos. En el caso colombiano, por ejemplo, se ha reconocido que el derecho a la reparación integral debe ser considerado como un derecho fundamental para las víctimas del conflicto armando ${ }^{40} ;$ interpretación ésta que, para autores como Sergio Rojas Quiñones, debe ser extensiva a todas las víctimas de un evento de responsabilidad civil ${ }^{41}$. Así pues, en estos casos,

39 "La Corte ha admitido que algunas garantías procesales, -y entre ellas el derecho de defensa y contradicción- no son absolutas y pueden ser limitadas por el legislador, siempre que no se vea afectado su núcleo esencial, la limitación responda a criterios de razonabilidad y proporcionalidad, y no se desconozcan otros derechos fundamentales, como puede ser el derecho a la igualdad. En todo caso, ha señalado que la función, tanto del legislador como del juez constitucional, es tratar de lograr que todos los principios y derechos que eventualmente puedan entrar en tensión a la hora de regular los términos judiciales sean garantizados en la mayor medida posible". Corte Constitucional de Colombia. Sentencia C-371 del 11 de mayo de 2011. M.P. Luis Ernesto Vargas Silva.

40 " $[. .$.$] 65. Luego de revisar los estándares de protección internacional y la forma en que$ encuentran un correlato en nuestro orden constitucional, esta Corporación ha señalado que la restitución constituye un componente preferente y principal del derecho fundamental a la reparación integral de las víctimas del conflicto armado. En la sentencia C-820 de 2012, la Corte sostuvo que el derecho a la restitución es "la facultad que tiene la victima despojada o que se ha visto obligada a abandonar de manera forzada la tierra, para exigir que el Estado le asegure, en la mayor medida posible y considerando todos los intereses constitucionales relevantes, el disfrute de la posición en la que se encontraba con anterioridad al abandono o al despojo".[...]" Corte Constitucional de Colombia. Sentencia C-330 del 23 de junio de 2016. M.P. María Victoria Calle Correa.

42 En torno a lo esgrimido por la Corte Constitucional, en cuanto a que el derecho a la reparación integral tiene el carácter de fundamental de cara a las víctimas del conflicto armando, Rojas Quiñones, señala lo siguiente: "Pero, cy qué de las demás víctimas que no provienen del conflicto? En contextos ajenos al de la justicia transicional como es, por ejemplo, el de la reparación integral puramente civil, cexiste también un derecho fundamental tutelable? En este punto el ejercicio jurisprudencial se ha quedado corto. Sin perjuicio de un estudio más detallado en el que hemos abordado la cuestión, lo cierto es que, considerados en su justa dimensión los argumentos propuestos por la Corte Constitucional, no existe una razón por la cual las víctimas ajenas al conflicto armado deban enfrentar un tratamiento menos favorable o menos tuitivo. 
dado que estamos ante dos derechos fundamentales, es posible plantear que, en determinadas circunstancias, bajo un ejercicio de ponderación, el derecho de defensa y de contradicción del causante del daño puedan verse en cierto grado delimitado a fin de que prevalezca el derecho a la reparación integral.

Bajo tal entendido, resultaría abiertamente posible acometer un ejercicio de ponderación de derechos, conforme al cual, en el caso de los seguros obligatorios, deviene en proporcional y razonable el atenuar el escenario para el ejercicio del derecho de defensa por parte del asegurado, en aras de despejar los caminos procesales para que la víctima pueda percibir la indemnización garantizada mediante la póliza correspondiente. Al respecto, nótese lo señalado por la jurisprudencia contencioso administrativa colombiana en relación con la posibilidad de balancear los derechos a la reparación integral y derechos procesales indudablemente relevantes, como el derecho a una decisión de mérito congruente:

"[...] como quiera que el presente asunto desborda la órbita del derecho subjetivo de las víctimas y de los perjudicados con el daño, en la medida que se afectó de manera grave el derecho a la salud de los niños, se torna necesario decretar e implementar garantías de no repetición, a efectos de proteger la dimensión objetiva del derecho antes precisado. Cuando el juez de lo contencioso administrativo aprecia la vulneración grave de la dimensión objetiva de un derecho, puede adoptar medidas de justicia restaurativa a efectos de que sea reestablecido el núcleo del

Si la reparación integral obedece a una necesidad de justicia para quien ha sido dañado, no podría sostenerse que para unas víctimas este es un derecho fundamental mientras que para otras no, sin asumir consecuencialmente que algunas tienen derecho a más justicia que otras, lo que es un contrasentido evidente.

Puesto en otros términos, no existe una razón, distinta a un absurdo lógico y jurídico, que permitiera justificar un tratamiento distintivo entre las víctimas, en desmedro de un grupo de ellas.

Lo anterior, por supuesto, no quiere decir que el contenido de la reparación sea idéntico: si bien la naturaleza jurídica debe ser misma, las circunstancias crónicas y agravatorias del conflicto armado imponen, evidentemente, un contenido diferente para la reparación específica de este grupo de afectados. Lo que no tiene sentido es afirmar que, además del contenido diferente, el solo hecho generador desvirtúa la naturaleza fundamental del derecho a la reparación para todas aquellas víctimas que no provengan del enfrentamiento bélico o de la violación de derechos humanos.

Con más veras si se tiene en cuenta la teoría de los derechos fundamentales por conexidad: en el fallo de la Corte Constitucional pareciera ser que se le atribuye a la reparación integral el carácter de fundamental por su inescindible y necesaria conexión con otros derechos fundamentales como el de la dignidad y el acceso a la justicia. Pues bien, estos derechos fundamentales se verían igualmente trastocados si a una víctima ajena al conflicto armado se le negara la consabida reparación. De ahí que no pueda diferenciarse entre las distintas víctimas y, de contera, la exigibilidad de sus derechos por la vía de la acción de tutela con todos los demás requisitos que son aplicables". ROJAS QuiÑONES, SERGIO. La reparación integral: ¿un derecho fundamental susceptible de tutela?, www.ambitojuridico.com, (mayo, 2015), p. 2. 
derecho o interés constitucionalmente protegido, al margen de que el trámite procesal sea el del grado jurisdiccional de consulta o la resolución de un recurso de apelación único. Lo anterior, toda vez que el principio de la no reformatio in pejus, como expresión de la garantía del derecho al debido proceso sólo tiene restricción en la órbita indemnizatoria del principio de reparación integral. En efecto, la jurisprudencia de la Corporación ha precisado que si existe una colisión entre el principio de reparación integral con los principios de congruencia procesal y de jurisdicción rogada, estos últimos deben ceder frente al primero en cuanto concierne a las medidas de satisfacción, rehabilitación, y garantías de no repetición, toda vez que el parámetro indemnizatorio, esto es, el reconocimiento de los perjuicios materiales e inmateriales sí está amparado por los citados principios del proceso que tienden a garantizar el derecho de defensa del demandado. ${ }^{42}$.

En segundo lugar, es pertinente señalar que, debido a que la teleología de los seguros obligatorios es hacer más sencilla, ágil y efectiva la compensación de las víctimas de actividades usualmente dañinas pero de importancia social, es posible sostener que, como quiera que el derecho sustancial no sólo debe primar, sino que debe ser plenamente realizado y desarrollado por las normas instrumentales o adjetivas (art. 228 ${ }^{[43]}$ Constitución de Colombia), se justifica el hecho que el derecho de defensa, sin anular su núcleo esencial, ceda razonablemente ante la necesidad que la acción directa en los seguros obligatorios cumpla su finalidad práctica.

\section{CONCLUSIONES}

El artículo 87 de la Ley 45 de 1.990 permitió a las víctimas de siniestros amparados por un seguro de responsabilidad civil acudir, mediante el ejercicio de la acción directa, ante las compañías aseguradoras para obtener el pago de los perjuicios que se les hubieren causado. No obstante, el ejercicio de tal facultad ha resultado problemática en la práctica judicial, toda vez que al concebirse por la jurisprudencia de la Corte Suprema de Justicia que entre el asegurado y la aseguradora se configura un litisconsorcio de carácter facultativo, es posible que se incoen procesos en contra de las compañías aseguradoras en los que se debata sobre la responsabilidad del asegurado, pero que no cuenten con la comparezca de este último.

42 Consejo de Estado. Sala de lo Contencioso Administrativo. Sección Tercera. Sentencia del 19 de agosto de 2019. C.P. Enrique Gil Botero. Rad. 1997-03225-01 (18364).

43 "La Administración de Justicia es función pública. Sus decisiones son independientes. Las actuaciones serán públicas y permanentes con las excepciones que establezca la ley y en ellas prevalecerá el derecho sustancial. Los términos procesales se observarán con diligencia y su incumplimiento será sancionado. Su funcionamiento será desconcentrado y autónomo" Corte Constitucional de Colombia. Sentencia T-743 del 24 de junio de 2008 M.P. Manuel Jose Cepeda Espinosa. 
Quienes defienden la posición jurisprudencial en comento han argüido que no se vulnera el derecho de defensa del asegurado en tales situaciones, por cuanto la sentencia que se profiera en los procesos que se adelanten en contra de la aseguradora sin la participación del asegurado no hacen tránsito a cosa juzgada en contra de este último. No obstante, este argumento pierde de vista que lo resuelto en la sentencia que se profiera en el primer trámite procesal en relación con la responsabilidad del asegurado será difícilmente modificado -dada las características del esquema procesal vigente en la legislación colombiana- por el Juez que conozca del proceso que la víctima eventualmente inicie en contra de asegurado. De hecho, salvo eventos extraordinarios, existirán muy pocos incentivos para que el juez que conozca del segundo proceso falle de manera diferente a su predecesor.

De esta manera, y debido a que la participación del asegurado se hace deseable en los procesos que se sigan en contra de la aseguradora con el propósito de garantizar plenamente el derecho de defensa del asegurado, la mejor alternativa que existe para resolver tal inconveniente es concebir que entre la compañía aseguradora y el asegurado se configura un litisconsorcio de carácter necesario. De este modo, se garantizará que el asegurado pueda defenderse frente a las imputaciones que se le realice, y se evitará que se profieran sentencias contradictorias, ya que, bien podría suceder, que en el primer proceso se condene a la compañía aseguradora y en el segundo se exonere al asegurado por un mismo evento dañoso.

Sin embargo, tal conclusión sólo puede ser aplicable a los seguros de responsabilidad civil de carácter voluntario, dado que la extensión de la misma a los seguros de carácter obligatorio podría generar que los objetivos de justicia distributiva que subyacen a este tipo de contratos difícilmente se materialicen. En efecto, es posible afirmar que obligar a la víctima a que vincule en un sólo proceso a la compañía aseguradora y al asegurado podría desincentivar el ejercicio de la acción directa, produciendo que muchos de estos terceros afectados no resulten indemnizados, a pesar de que tales seguros sean concebidos por el legislador precisamente para lograr el resarcimiento de los perjudicados en la mayoría de los eventos. Por ello, en este caso, el derecho de defensa del asegurado está llamado a ceder en beneficio de las víctimas de actividades cuyo aseguramiento resulte obligatorio.

Todo lo contrario ocurre en lo atinente al ejercicio de la acción directa en los seguros de carácter voluntario, toda vez que en estos eventos sí debería exigirse a la víctima que vincule en un mismo proceso a la compañía aseguradora y al asegurado, puesto que con la contratación de tales seguros no se busca que la víctima sea indemnizada en todos los eventos (ya que el causante del daño puede no tener contratado un seguro ni tener los recursos suficientes en su patrimonio para reparar los perjuicios causados), sino que la misma, en los supuestos en que exista un seguro de responsabilidad civil, reciba la indemnización que allí fue convenida y no tenga que iniciar dos procesos 
diferentes para obtener la reparación de sus perjuicios (uno en contra del asegurado y otro en contra de la compañía aseguradora una vez obtenga la declaratoria de responsabilidad del asegurado). Es decir, en este último caso, no existen razones para que el derecho de defensa del asegurado tenga que ceder de manera alguna en beneficio de las víctimas, sobre todo cuando es claro que los objetivos de justicia correctiva que subyacen al ejercicio de la acción directa en el seguro de responsabilidad voluntario resultan afines con la configuración de un litisconsorcio necesario en la hipótesis bajo estudio.

\section{BIBLIOGRAFÍA}

\section{DOCTRINA}

Arraz, Mariano Hernández. La Acción Directa como Instrumento de Garantía. Madrid: publicaciones del Real Colegio de España, 2005.

Coleman, Jules L. Riesgos y daños. Madrid: Marcial Pons, 2010.

Coloma Correa Rodrigo, ¿Realmente importa la sana crítica?, revista chilena de derecho, vol. 39, n. 3 (2012), p. 765.

Devis Echandía, Hernando. Teoría General del Proceso. Buenos Aires: Editorial Universidad, 1985.

Diaz-Granados, Juan Manuel. El Seguro de Responsabilidad Civil. Bogotá: Universidad del Rosario, 2012.

Grande Seara, Pablo. La extensión subjetiva de la cosa juzgada en el proceso civil (Valencia: Tirant lo Blanch, 2008), p. 427.

GUILLEN, Víctor Fairén. Teoría general del derecho procesal. Revista de derecho privado del Instituto de Investigaciones Jurídicas. Serie G estudio, n. ${ }^{\circ} 133$ (1955), p. 143.

GaVIRIA FajARDO, Ricardo. El seguro Obligatorio de Accidentes de Tránsito, www. fasecolda.com, (2011), p. 148.

ISAZA POSSE, MARIA CRISTINA. El seguro de responsabilidad civil extracontractual Dificultades que se presentan en el mercado colombiano, Revista IberoLatinoamericana de seguros JAVEGRAF, n. ${ }^{\circ} 24$ (2006), p. 152.

Jairo Parra QuiJano, Manual de derecho probatorio. Bogotá: Librería del profesional, 1992. 
JARAMILlo JARAmillo, CARlos IGNACIO. La acción directa en el seguro de responsabilidad civil en América Latina, Revista Ibero-Latinoamericana de Seguros JAVEGRAF, n. ${ }^{\circ} 8$ (1996), p. 149.

Juan Montero Aroca, La intervención adhesiva simple. Contribución al estudio de la pluralidad de partes en el proceso civil. Barcelona: Editorial HispanoEuropea, 1972.

Lagos Villarreal, Osvaldo. Fundamento y Régimen de la Vinculación entre el Tercero Perjudicado y el Asegurador Voluntario de Responsabilidad Civil: Una Cuestión de Derecho Privado, Revista Chilena de Derecho Privado, n. ${ }^{\circ}$ 26 (2016), p. 187.

López Blanco, Hernán Fabio. Código General del Proceso. Parte General. Bogotá: Dupré Editores, 2017.

NaVAs Herrera, María Fernanda. Víctimas de accidentes de tránsito. Su protección en el mundo a través del aseguramiento obligatorio y breve referencia al sistema implantado en Colombia, Revista Ibero-Latinoamericana de Seguros JAVEGRAF, n. ${ }^{\circ} 19$ (2009), p. 19.

Ordoñez, Andrés. El Contrato de Seguro. Ley 389 de 1997 y Otros Estudios. Bogotá: Universidad Externado de Colombia, 1998.

Ossa G J, Efrén. Teoría General del Seguro -El contrato. Bogotá: Temis,1991.

PAPAYANNIS, Diego M. Comprensión y justificación de la responsabilidad extracontractual, Madrid: Marcial Pons, 2014.

PARRA QUIJANO, JAIRO. Manual de derecho probatorio (Bogotá: Librería del profesional, 2007), p. 248.

PATIÑo Escobar Andrés José, El derecho de subrogación en materia de SOAT en Colombia, tesis de Grado para optar al título de especialista en derecho privado, Universidad Pontificia Bolivariana, 2012

Reglero Campos, Fernando. Ley del Contrato de Seguro (Navarra: Aranzadi, 2007), p. 1103.

Rodrigo Coloma CORREA, ¿Realmente importa la sana crítica?, revista chilena de derecho, vol. 39, n. ${ }^{\circ} 3$ (2012), pp. 754-755.

ROJAS QUIÑNONES, SERGIO. La reparación integral: cun derecho fundamental susceptible de tutela?, www.ambitojuridico.com, (mayo, 2015), p. 2. 
ROSANVALLON PieRRE. La nueva cuestión social repensar el estado providencia. Buenos Aires: Ediciones Manantía, 1995.

SÁnCHEZ CALERO, FERnANDO. Líneas generales de la evolución de la responsabilidad civil y de su seguro, Revista Ibero-Latinoamericana de Seguros JAVEGRAF, n. ${ }^{\circ}$ 15 (2000), p. 65.

VIGIL-DUATE, ÁNGEL. La acción directa del tercero perjudicado contra el asegurador de responsabilidad civil, Revista Ibero-Latinoamericana de Seguros, vol. 17, n. ${ }^{\circ}$ 28 (2008), p. 46.

\section{JURISPRUDENCIA}

Corte Suprema de Justicia. Sala de Casación Civil. Sentencia del 18 de mayo de 1994. M.P. Edgardo Villamil Portilla. Rad. 4106.

Corte Suprema de Justicia. Sala de Casación Civil. Sentencia del 10 de febrero de 2005. M.P. Jaime Alberto Arrubla. Rad. 7614.

Corte Constitucional de Colombia. Sentencia C.202 del 8 de marzo de 2005. M.P. María Victoria Correa.

Corte Constitucional de Colombia. Sentencia T-743 del 24 de junio de 2008. M.P. Manuel Jose Cepeda Espinosa.

Corte Constitucional de Colombia. Sentencia C-371 del 11 de mayo de 2011. M.P. Luis Ernesto Vargas Silva.

Corte Suprema de Justicia. Sala de Casación Civil. Sentencia del 5 de julio de 2012. M.P. Edgardo Villamil Portilla. Rad. 2005-00425-01.

Corte Constitucional de Colombia. Sentencia C-330 del 23 de junio de 2016. M.P. María Victoria Calle Correa.

\section{NORMAS}

Decreto 410 de 1971. Por el cual se expide el Código de Comercio. Diario Oficial n. ${ }^{\circ} 33.339$ del 16 de junio de 1971.

Ley 33 de 1986. Por la cual se modifica el Código Nacional de Tránsito Terrestre y se dictan otras disposiciones. Diario Oficial n. ${ }^{\circ} 37.336$ del 6 de febrero de 1986

Ley 1564 de 2012. Por medio de la cual se expide el Código General del Proceso y se dictan otras disposiciones. Diario Oficial n. ${ }^{\circ} 48.489$ de 12 de julio de 2012. 